\title{
mRNA Localization and Translational Control in Drosophila Oogenesis
}

\author{
Paul Lasko \\ Department of Biology, Bellini Life Sciences Building, McGill University, Montréal, Québec H3G 0B1, Canada \\ Correspondence: paul.lasko@mcgill.ca
}

Localization of an mRNA species to a particular subcellular region can complement translational control mechanisms to produce a restricted spatial distribution of the protein it encodes. mRNA localization has been studied most in asymmetric cells such as budding yeast, early embryos, and neurons, but the process is likely to be more widespread. This article reviews the current state of knowledge about the mechanisms of mRNA localization and its functions in early embryonic development, focusing on Drosophila where the relevant knowledge is most advanced. Links between mRNA localization and translational control mechanisms also are examined.

Cell polarization requires proteins to be asymmetrically localized, which can be achieved by localizing specific mRNAs to particular regions of the cytoplasm so that their translation occurs only there mRNA localization is often inefficient, thus it is usually coupled to translational control mechanisms that repress translation of unlocalized mRNA while allowing translation of the localized mRNA to proceed. Genome-wide analysis of mRNA localization in early Drosophila embryos showed that the majority of mRNAs are asymmetrically distributed (Lécuyer et al. 2007; Tomancak et al. 2007).

The Drosophila oocyte is a valuable model system to study mRNA localization and translational control. In organisms such as Drosophila in which zygotic transcription does not commence until many nuclear or cellular divisions have occurred, translational control of maternally encoded mRNAs necessarily has a widespread role in regulating gene expression so that the initial stages of development can proceed. Drosophila oocytes develop within multicellular entities called egg chambers (King 1970). Each egg chamber contains a syncytium of 16 germ line cells (called cystocytes), which are connected by cytoplasmic bridges (ring canals). Only one cystocyte adopts an oocyte fate and completes meiosis while its siblings develop into polyploid nurse cells. The nurse cells are highly active in transcription and translation, and mRNAs and proteins expressed in those cells are transferred to the oocyte through the ring canals to the oocyte, whereas the oocyte nucleus is largely quiescent. Toward the end of oogenesis, the nurse cells expel their cytoplasm into the oocyte and afterward undergo apoptosis. The germ line cyst is surrounded by a single layer of follicle cells (the follicular epithelium), which not only secrete the eggshell but also play pivotal roles in signaling pathways that help establish oocyte polarity.

Editors: John W.B. Hershey, Nahum Sonenberg, and Michael B. Mathews

Additional Perspectives on Protein Synthesis and Translational Control available at www.cshperspectives.org

Copyright (C) 2012 Cold Spring Harbor Laboratory Press; all rights reserved; doi: 10.1101/cshperspect.a012294

Cite this article as Cold Spring Harb Perspect Biol 2012;4:a012294 
P. Lasko

\section{FOUR mRNAs ESSENTIAL FOR EMBRYONIC PATTERN SPECIFICATION ARE LOCALIZED TO THREE CYTOPLASMIC REGIONS OF THE DROSOPHILA OOCYTE: ANTERIOR, POSTERIOR, AND ANTERODORSAL}

The future embryonic body axes are specified during oogenesis, and mRNA localization and translational control are crucial for this (Bastock and St Johnston 2008; Kugler and Lasko 2009; Becalska and Gavis 2009). Four localized mRNAs, oskar (osk), nanos (nos), bicoid (bcd), and gurken (grk), are the key players in embryonic axis specification (Fig. 1), and for this reason their regulation has been especially well studied. The anterior-posterior axis is elaborated through localization of $b c d$ mRNA to the anterior of the oocyte, and localization of osk and nos mRNAs to the posterior of the oocyte. In late-stage oocytes, $b c d$ and nos are translationally repressed. This repression is relieved after fertilization, and the corresponding proteins are produced in opposing gradients that initiates a cascade of zygotic gene expression that directs anterior-posterior patterning. As will be discussed in more detail below, formation of the anterior-to-posterior Bcd gradient is primarily achieved through localization of its mRNA at the anterior pole, whereas formation of the posterior-to-anterior Nos gradient is achieved through translational repression of its mRNA by Bcd, and enrichment of its mRNA at the posterior where it is translationally active.

osk mRNA begins to be translated during mid-oogenesis to nucleate the formation of the pole plasm, a specialized cytoplasm at the

A

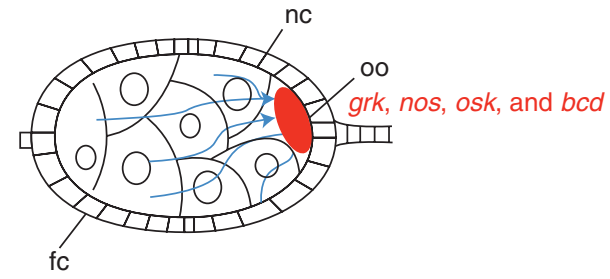

B

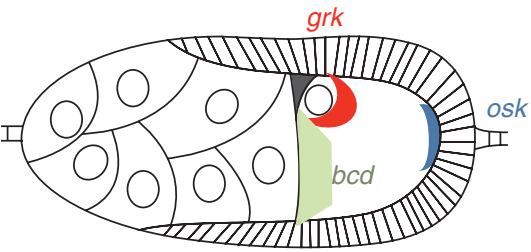

C

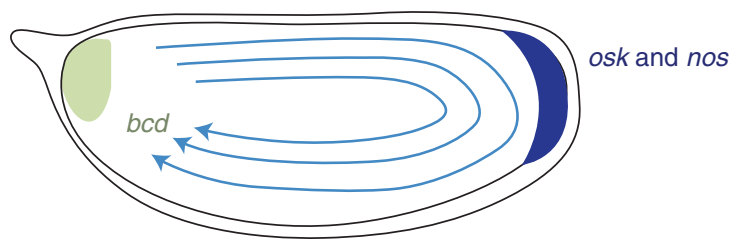

Figure 1. Localization of patterning mRNAs in Drosophila oogenesis. (A) In early oogenesis, several mRNAs, including grk, nos, osk, and $b c d$, are transported from the nurse cells through cytoplasmic bridges called ring canals into the oocyte. This involves minus-end directed transport along microtubules (blue arrows) mediated by the dynein motor complex. Abbreviations: nc, nurse cells, fc, follicle cells, oo, oocyte. $(B)$ In mid-oogenesis, osk mRNA localizes to the posterior of the oocyte, grk mRNA localizes to the anterodorsal corner in close association with the oocyte nucleus, and $b c d$ mRNA localizes to the anterior pole. $(C)$ In late oogenesis, centrifugal cytoplasmic streaming (delineated by arrows) coupled with posterior anchoring brings about a further posterior enrichment of osk mRNA as well as posterior enrichment of nos mRNA. The distribution of $b c d$ mRNA at the anterior pole is further refined. 
posterior of the oocyte that contains large RNP complexes called polar granules that include posterior and germ cell determinants such as Nos, and which is therefore required in the embryo for posterior patterning and primordial germ cell specification. Like nos, osk mRNA localizes to the posterior pole where it is active, and is translationally silenced elsewhere. Grk, an epidermal growth factor receptor (EGFR) ligand, is crucial for the establishment of both the anterior-posterior and dorsal-ventral axes during oogenesis (González-Reyes et al. 1995; Roth et al. 1995). Grk is secreted from the oocyte to locally activate EGFR in adjacent follicle cells, and restricting its deployment enables it to specify spatial information. During early oogenesis, EGFR activation by Grk assigns posterior fate to a subpopulation of follicle cells that is essential for polarizing the oocyte and establishing anterior-posterior polarity. Later, Grk produced from localized mRNA at the anterodorsal corner of the oocyte specifies the dorsalventral axis by inducing dorsal fate in the follicle cells immediately adjacent.

\section{CIS-ACTING ELEMENTS THAT ARE ESSENTIAL FOR MRNA LOCALIZATION USUALLY INCLUDE STEM-LOOP STRUCTURES}

Transport of many mRNAs, including $g r k, b c d$, and osk, from the nurse cells to the oocyte occurs prior to overall cytoplasmic transfer, and proceeds via minus end-directed transport on the microtubule cytoskeleton that is driven by the dynein motor complex (Clark et al. 2007). Two proteins, Egalitarian (Egl) and Bicaudal-D (Bic-D), working in concert are directly responsible for linking mRNAs to dynein and to microtubules (Fig. 2) (Navarro et al. 2004; Dienstbier et al. 2009). Although associating with the localization element of the mRNA to be transported, the amino-terminal region of Egl directly binds to the carboxyl-terminal domain (CTD) of Bic-D (Dienstbier et al. 2009), which in turn interacts with dynein through dynactin (Hoogenraad et al. 2003). Egl also interacts with dynein light chain. A structural study using NMR spectroscopy indicates that a stem-loop with two double-stranded RNA

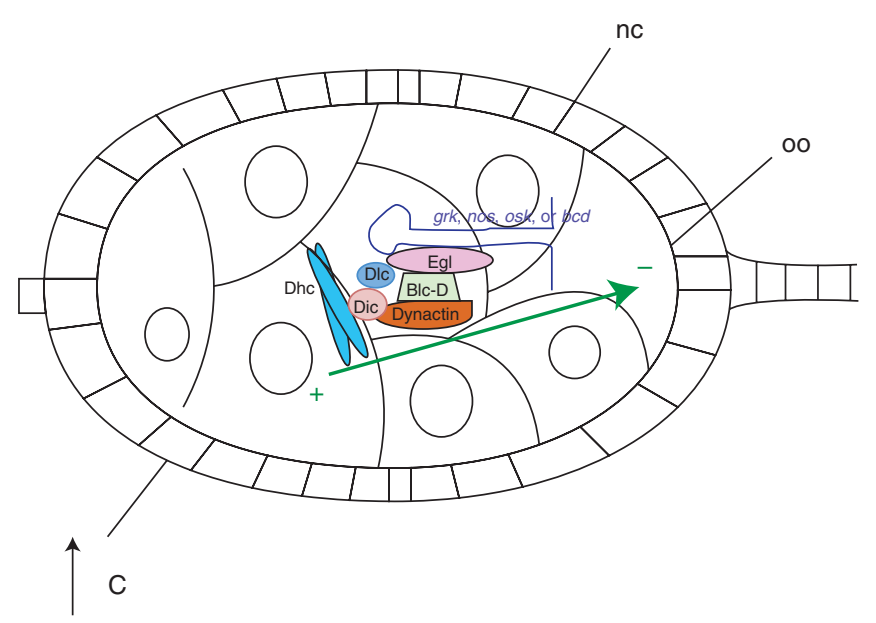

Figure 2. Model for linking mRNAs to the microtubule cytoskeleton for minus-end directed transport. Egalitarian (Egl) interacts directly with localization signals on mRNAs, with the carboxy-terminal end of Bicaudal-D (Bic-D), and with dynein light chain (Dlc). Bic-D interacts directly with dynactin, which in turn binds to dynein through its intermediate chain (Dic). Dynein heavy chain (Dhc) interacts with microtubules (green arrow) and catalyzes movement toward the minus-end. Although both in vivo and in vitro evidence exists to support this model for some instances of dynein-directed minus-end transport, and Egl and Bic-D are required for accumulation of $g r k$, nos, osk, and $b c d$ mRNAs into the oocyte, it has not yet been directly shown that this mechanism governs this particular localization event. 
P. Lasko

helices in an unusual $\mathrm{A}^{\prime}$-form conformation (Arnott et al. 1972) is a crucial recognition site for this complex (Bullock et al. 2010).

\section{ANTERIOR TARGETING, ANCHORING, AND TRANSLATIONAL REGULATION OF bcd}

Localization of $b c d$ mRNA proceeds through several steps (St Johnston et al. 1989). The initial phase of $b c d$ localization to the anterior cortex of the oocyte requires Exuperantia (Exu) protein (Berleth et al. 1988; Cha et al. 2001; Mische et al. 2007). Exu-containing ribonucleoprotein particles (RNPs) display dynamic movements that are very similar to those displayed by injected fluorescent $b c d$ mRNA, and GFP-Exu is recruited to injected $b c d$ mRNA (Theurkauf and Hazelrigg 1998; Wilhelm et al. 2000). Exu is phosphorylated by the Par-1 kinase, and this posttranslational modification of Exu is important for anterior Exu and $b c d$ mRNA localization (Riechmann and Ephrussi 2004).

Genetic evidence has implicated several additional proteins as involved in anchoring of $b c d$ at the anterior cortex, including Staufen (Stau), an RNA binding protein, Swallow (Swa), the $\gamma$ tubulin ring complex components $\gamma \mathrm{Tub} 37 \mathrm{C}$, dGrip75 and dGrip128, and the microtubuleassociated protein Mini Spindles (Msps) (Ferrandon et al. 1994; Schnorrer et al. 2002; Moon and Hazelrigg 2004; Vogt et al. 2006; Weil et al. 2006). However, the roles of some of the molecules may be indirect. Super-resolution microscopy has shown that Swa, which was once thought to link bcd mRNA containing RNPs to the dynein motor complex, actually does not precisely colocalize in the same particles as bcd (Weil et al. 2010). Rather, Swa appears to regulate the actin cytoskeleton, which in turn could be essential for anchoring $b c d$ mRNA. Unlike Swa, Stau is found in the same particles as bcd and appears to be directly involved in recruiting it to the dynein motor (Weil et al. 2010). bcd mRNA anchoring also requires the ESCRT-II complex. The three conserved ESCRT complexes (ESCRT-I, -II, and -III) collaborate to mediate endosomal sorting; only ESCRT-II is required for anterior $b c d$ mRNA localization, however, suggesting that a different mechanism is involved (Irion and St Johnston 2007). One subunit of ESCRT-II, VPS36, binds directly to sequences in the $b c d 3^{\prime} \mathrm{UTR}$ and localizes to the anterior of the oocyte in a $b c d$ mRNA-dependent but stau-independent manner, indicating that ESCRT-II acts upstream of Stau in the bcd localization pathway. A recent genetic screen has identified short stop, which encodes a spectroplakin protein that binds both actin and microtubules, and $\mathrm{Su}$ (Mir)2, whose identity is unknown, as encoding other potential factors involved in $b c d$ anchoring (Chang et al. 2011).

\section{FORMATION OF THE ANTERIOR- POSTERIOR BICOID PROTEIN GRADIENT FROM THE LOCALIZED bcd mRNA}

As mentioned above, in the early Drosophila embryo, an anterior-to-posterior gradient of Bcd protein is established from its anteriorly localized mRNA. Bcd is a transcription factor, acting as a graded morphogen that influences developmental decisions in a concentration-dependent manner (Driever and Nüsslein-Volhard 1988). As nuclei migrate during syncytial divisions into different regions of the embryo, they activate expression of various sets of patterning genes based on the concentration of $\mathrm{Bcd}$ they encounter, and thus on their position along the anterior-posterior axis.

Despite indications that this classic model of Bcd function is insufficient to explain results observed when the Bcd gradient is physically perturbed, flattened, or abolished (Lucchetta et al. 2008; Löhr et al. 2009; Ochoa-Espinosa et al. 2009), it remains clear that Bcd is an important morphogen and the characteristics of its graded distribution need to be carefully controlled. Substantial attention has therefore been given in recent years as to how exactly the Bcd gradient is generated, taking into account the physical properties of the embryonic cytoplasm and the diffusion characteristics of $b c d$ mRNA and Bcd protein. Initial attempts at modeling the Bcd gradient considered the mRNA as a point source and postulated that protein diffusion was the dominant means in which the gradient was produced (Houchmandzadeh et al. 2002; Gregor et al. 2007a,b), along with a constant 
amount of degradation. This model, however, does not fully agree with measured diffusion constants that predict a shorter length scale for the Bcd gradient than observed (Gregor et al. 2007b). Subsequently, it was realized that formation of the $b c d$ mRNA gradient that presages the protein gradient is critical for establishing the latter (Spirov et al. 2009). Quantitative measurement of $b c d$ mRNA and Bcd-GFP protein in real time indicates that the mRNA distribution is more tightly restricted to the anterior than the protein, implying that protein movement from the graded mRNA distribution makes an essential contribution to producing the protein gradient (Little et al. 2011). The recent discovery that Fates-shifted, a ubiquitin ligase substrate specificity receptor that targets Bcd for degradation, is required for formation of a normal Bcd gradient and for correct anterior-posterior patterning, makes it evident that regulation of $\mathrm{Bcd}$ protein stability is an important aspect of how the gradient is produced (Liu and Ma 2011).

Translational control appears not to be involved in establishing the Bcd gradient, but it is involved in temporal regulation because localized $b c d$ mRNA is apparent from mid-oogenesis when Bcd protein is not detectable. Mutations in pumilio (pum), which encodes an RNA binding protein, or deletion of a consensus Pum binding site in the $b c d 3^{\prime}$ UTR leads to increased Bcd expression during embryogenesis (Gamberi et al. 2002), but it is unknown whether this mechanism mediates translational repression during oogenesis.

\section{TARGETING osk AND nos mRNAs TO THE POSTERIOR POLE PLASM}

Both osk and nos are enriched at the posterior pole of the oocyte in a region termed the pole plasm, and their translation within the oocyte and syncytial embryo is restricted to that region.

\section{osk Localization Is Microtubule-Dependent but Anchoring Requires F-Actin}

As discussed earlier for $b c d$, initial loading of osk into the oocyte also proceeds through microtubule-dependent motor driven transport, and like $b c d$, osk is initially transported via a minus-end directed dynein-mediated process. Beginning in mid-oogenesis, osk begins to accumulate in the posterior of the oocyte, and this localization is an essential first step for pole plasm assembly.

Localization of osk mRNA to the pole plasm requires cis-acting elements in its $3^{\prime}$ UTR and nuclear imprinting of unspliced osk with exon junction complex components (Mago Nashi, Y14, eIF4AIII) and Hrp48 (Hachet and Ephrussi 2004; Huynh et al. 2004; Palacios et al. 2004; Yano et al. 2004). Although splicing of the first intron of osk pre-mRNA is essential for its localization, reporter mRNAs lacking introns but containing osk $3^{\prime}$ UTR elements can localize via RNA:RNA dimerization with imprinted endogenous osk, even if that endogenous osk cannot be translated (Jambor et al. 2011). osk localization also requires a specific association with Stau, a RNA binding protein that interacts with certain stem-loop structures in the $3^{\prime}$ UTR (Micklem et al. 2000). Posterior localization of osk is microtubule dependent, but unlike the earlier phase, it is driven by the plus-end directed motor kinesin. Real-time analysis of the movements of individual osk-containing particles shows they are not highly directed, and that posterior enrichment is accomplished through a collection of random walks that is slightly biased toward the posterior, reflecting a similar weak enrichment of microtubule plus-ends at the oocyte posterior (Zimyanin et al. 2008).

A later stage of osk localization takes advantage of rapid movements of the oocyte cytoplasm that occur in later oogenesis and involves anchoring of the mRNA in the posterior pole plasm (Sinsimer et al. 2011). Anchoring oskcontaining mRNPs at the posterior requires specifically the longer of two Osk protein isoforms, the endocytic pathway, and rearrangements of the F-actin cytoskeleton (Vanzo et al. 2007; Tanaka et al. 2011). Actomyosin-based transport is implicated in short-range movements that sharpen the polarization of osk mRNA distribution at the posterior pole (Krauss et al. 2009). Osk itself induces the formation of long F-actin projections from the posterior cortex into the pole plasm, corroborating the link 
P. Lasko

between osk anchoring and the actin cytoskeleton (Babu et al. 2004).

Posterior Accumulation of nos Is Inefficient and Proceeds as a Consequence of Cytoplasmic Streaming

nos mRNA also specifically accumulates in the posterior pole plasm, but its localization is inefficient, with only an approximate $4 \%$ enrichment in the posterior half of early embryos (Bergsten and Gavis 1999). Translational repression is therefore the primary mechanism for excluding Nos outside the posterior. In fact, localization of nos mRNA is dispensable for somatic patterning, although it is required for germ cell development (Gavis et al. 2008). nos mRNA moves throughout the oocyte during a period of rapid cytoplasmic streaming that commences in mid-oogenesis, and gradually accumulates in the pole plasm through an anchoring mechanism (Forrest and Gavis 2003; Weil et al. 2006). Rumpelstiltskin (Rump), an hnRNP M homolog, binds to one of several $3^{\prime}$ UTR elements involved in nos mRNA localization and acts directly in its localization (Jain and Gavis 2008). Recently, mutations in aubergine (aub) were shown to affect nos localization, and Aub protein can be copurified with the nos $3^{\prime}$ UTR and with Rump (Becalska et al. 2011). Although Aub has been implicated in silencing of retrotransposons in the germline, its function in nos localization appears unrelated to this, as mutations in other genes involved in retrotransposon silencing do not have a similar effect on nos.

\section{grk mRNA LOCALIZATION IS A MICROTUBULE-DEPENDENT PROCESS}

grk mRNA, though mostly transcribed in the nurse cells, accumulates in the oocyte and colocalizes with the oocyte nucleus throughout much of oogenesis. In early oogenesis the oocyte nucleus is located at the posterior, and grk mRNA accumulates there. Later, when the oocyte nucleus moves to an anterodorsal position, grk mRNA forms a crescent between the apical surface of the nucleus and the neighboring region of the cortex. Transcription of grk from the oocyte nucleus is not essential for this, because a similar distribution is observed in mosaic egg chambers in which the oocyte nucleus is homozygous for an RNA-null grk allele (Caceres and Nilson 2005). Further, grk transcription from the oocyte nucleus is not required for patterning, as dorsal follicle cell fates and the dorsalventral embryonic axis are specified in these mosaics.

Initial transport of grk mRNA from the nurse cells to the oocyte uses the dynein and Bic-D/Egl dependent pathway described above for $b c d$ and osk. grk first accumulates along the anterior cortex, then it is transported laterally toward the oocyte nucleus (MacDougall et al. 2003; Jaramillo et al. 2008). This second phase of grk transport also depends on dynein and the microtubule cytoskeleton, and the oocyte nucleus appears to nucleate a distinct population of microtubules, which are thought to mediate lateral displacement (MacDougall et al. 2003; Januschke et al. 2006; Delanoue et al. 2007). There is some controversy about the nature of the cis-acting elements that are essential for $g r k$ localization. Studies of injected fluorescentlytagged grk mRNA implicated an element within the protein-coding region, termed the grk localization signal (GLS) as essential for both oocyte targeting and anterodorsal localization (Van De Bor et al. 2005). However, an analysis of localization of RNA produced from a series of modified grk transgenes indicates that the GLS is not sufficient for anterodorsal accumulation and that another element must be involved (Lan et al. 2010).

grk mRNA Anchoring also Requires Microtubules and Dynein

Microtubules and Dhc are required not only for grk mRNA transport but also for grk anchoring (Delanoue et al. 2007). How dynein switches from a dynamic to a static mode is not fully understood, but it clearly involves the activity of squid (sqd), which encodes an hnRNP, and perhaps K10, as mutations in either of those two genes abrogate stable grk accumulation at the anterodorsal corner (Jaramillo et al. 2008; Lan et al. 2010). 
mRNA Localization and Translational Control

PROTECTION FROM MATERNAL DEGRADATION CAN RESULT IN GERM CELL ACCUMULATION OF SPECIFIC mRNAs

Another mechanism that can lead to asymmetric distribution of mRNAs in the early embryo involves protection from RNA degradation. This was first established as a mechanism for enrichment of Hsp83 mRNA in the primordial germ cells (Bashirullah et al. 1999). Many maternallyexpressed mRNAs are degraded at the maternalto-zygotic transition, through the mediation of Smaug (Smg), a sequence-specific RNA binding protein that recruits the CCR4 deadenylase complex whose translation is drastically up-regulated on egg activation (Semotok et al. 2005; Tadros et al. 2007). Smg is also required for zygotic expression of the miR-309 cluster microRNAs, that mediate destabilization of a large set of maternal mRNAs (Bushati et al. 2008; Benoit et al. 2009). Degradation of unlocalized nos mRNA by Smg also involves recruitment of two transposon-encoded piwi-associated RNAs (piRNAs) that are complementary to sequences in the nos $3^{\prime}$ UTR (Rouget et al. 2010). Pumilio, another RNA-binding protein that can recruit the CCR4 deadenylase complex, has also been implicated in maternal transcript destabilization (Gerber et al. 2006 and see below). As primordial germ cells remain transcriptionally silent throughout early embryogenesis, maternal mRNAs whose degradation involves the action of zygotically transcribed molecules such as the miR-309 cluster may be preferentially stabilized in those cells (Walser and Lipshitz 2011).

\section{TRANSLATIONAL CONTROL OF osk IS ELABORATE}

osk mRNA is translated into two different isoforms, called Long Osk and Short Osk, that are expressed from different initiation codons in the osk mRNA (Markussen et al. 1995). Short Osk is sufficient to induce the accumulation of all other pole plasm components and to rescue the functions of osk in posterior patterning and germ cell specification, whereas Long Osk induces F-actin projections that are required for anchoring its mRNA at the posterior pole (Vanzo et al. 2007; Tanaka and Nakamura 2008).

In early oogenesis osk translation is repressed by RNA interference (RNAi), as mutations in several genes (including armitage, aubergine, cutoff, maelstrom, spindle-E, zucchini, and squash) involved in piRNA processes cause precocious osk translation in early oocytes (Findley et al. 2003; Cook et al. 2004; Tomari et al. 2004; Chen et al. 2007; Lim and Kai 2007; Pane et al. 2007). However, the axis patterning defects also observed in these mutants appear not to result directly from osk overexpression, but rather from defects in microtubule organization resulting from inappropriate activation of DNA damage signaling (Klattenhoff et al. 2007). As osk-containing mRNPs begin to localize to the oocyte posterior, translation is blocked through a different mechanism, operating at the level of ribosome recruitment, by Cup, an eIF4Ebinding protein that can interfere with the eIF4E-eIF4G interaction (Nakamura et al. 2004). Cup is recruited to osk by Bruno (Bru), an RNA binding protein with three RNA recognition motifs (RRMs). Through all three RRMs, Bru interacts directly with specific sequences (Bruresponse elements, or BREs) in the osk $3^{\prime}$ UTR, and represses its translation (Snee et al. 2008). Surprisingly, however, recent evidence indicates that, although Cup indeed induces translational repression, this does not require its eIF4E-binding activity and thus does not involve competition for eIF4G (Igreja and Izaurralde 2011; Jeske et al. 2011). Rather, Cup recruits the CCR4 deadenylase complex to its target mRNAs and reduces osk poly(A) tail length. Cup-associated mRNAs are not subsequently degraded, however, as they are protected by an amino-terminal regulatory domain of Cup through a mechanism that prevents decapping and requires one of its two eIF4E binding motifs.

Bru also represses translation in another manner, by packaging osk mRNA into heavy particles that render it inaccessible to the translational machinery (Chekulaeva et al. 2006). Further insight into the nature of silencing complexes came from a study of polypyrimidine tract binding protein (PTB), which is required for translational repression of osk during early 
P. Lasko

oogenesis (Besse et al. 2009). PTB binds with high affinity and cooperativity to the osk $3^{\prime}$ UTR, at several pyrimidine-rich sites, and catalyzes oligomerization of multiple osk mRNA molecules through bridging interactions.

Although mutation of BREs generally results in precocious osk translation, when endogenous osk mRNA is totally absent, translation from an osk transgene that lacks the distal pair of BREs but is otherwise complete (osk $\mathrm{C}^{-}$) is reduced. This was surprising as the opposite result would be expected from removing the BREs which were believed to be strictly repressor elements. In a genetic background in which osk mRNA with an intact $3^{\prime}$ UTR but an early stop codon is also expressed, osk $\mathrm{C}^{-}$is translated at a higher level. This implies that the distal pair of BREs is bifunctional, operating in different contexts as a repressor or an activator element. Further, these results indicate that the presence of osk mRNA with an intact $3^{\prime}$ UTR in osk mRNPs can facilitate activation of osk $\mathrm{C}^{-}$translation in trans, illustrating that mRNA molecules in the same RNP are coordinately regulated (Reveal et al. 2010).

Hrp48, an abundant RNA-binding protein that interacts with elements in both the $5^{\prime}$ and $3^{\prime}$ UTRs of $o s k$, is essential for osk localization and also contributes to its translational regulation (Huynh et al. 2004; Yano et al. 2004; Norvell et al. 2005). Live imaging of osk in hrp48 mutant ovaries implicate hrp48 in assembling osk into cytoplasmic particles (Mhlanga et al. 2009) and for its subsequent association with Staufen, a translational activator of osk (Kim-Ha et al. 1995; Micklem et al. 2000; Braat et al. 2004; Mhlanga et al. 2009). Glorund, an hnRNP F/H family member, also associates with Hrp48 and may be another component of these particles (Kalifa et al. 2009). Another RNA binding protein, Bicaudal-C (Bic-C), has been implicated genetically as a negative regulator of osk translation (Saffman et al. 1998). Bic-C directly recruits the CCR4 deadenylase complex to target mRNAs through an association with its NOT3/5 subunit (Chicoine et al. 2007). These targets could potentially include $o s k$.

Later in oogenesis, osk repression is alleviated, and translation activated, for the small pro- portion of osk RNA that is localized to the pole plasm. A key activator of osk translation is Orb, the Drosophila homolog of Xenopus cytoplasmic polyadenylation element binding protein (CPEB). Orb directly associates with two poly (A) polymerases, PAP and Wispy (Wisp). PAP is required during mid-oogenesis to promote Osk expression, whereas Wisp functions only during late oogenesis and in the early embryo (Benoit et al. 2009). An RNA binding protein that promotes CCR4-mediated deadenylation, Bicaudal-C, interacts with Orb, PAP, and Wisp, and possibly inhibits their association with target mRNAs (Castagnetti and Ephrussi 2003; Chicoine et al. 2007; Cui et al. 2008; Benoit et al. 2009).

\section{nos TRANSLATION IS ALSO HIGHLY REGULATED}

Nos protein is restricted to the posterior germ plasm by RNA localization and by translational repression of nos mRNA outside that region. nos regulation is mediated by a $90 \mathrm{nt}$ region of the $3^{\prime}$ UTR, termed the translational control element (TCE) (Crucs et al. 2000; Forrest et al. 2004). The TCE forms a complex secondary structure, and mutations that disrupt any portion of this structure prevent the binding of repressors of nos and render the entire element inactive (Forrest et al. 2004). Different parts of the TCE interact with different trans-acting factors at different developmental stages to ensure translational repression of unlocalized nos mRNA. During late oogenesis, repression is mediated by Glorund (Glo), an hnRNP F/H ortholog that binds to the stem of stem-loop III of the TCE (Kalifa et al. 2006). Another part of the TCE, the loop of stem-loop II, contains a Smaug Recognition Element (SRE), the binding site for Smg, which represses nos in early embryogenesis outside the pole plasm. Smg interacts with Cup, an eIF4E-binding protein that was discussed above in the context of osk regulation. The Cup-Smg interaction is required for Smg-mediated repression of SRE-containing mRNAs in embryo extracts (Nelson et al. 2004). Smg also interacts directly with the POP2 subunit of the CCR4 deadenylase complex, recruiting it to a 
mRNA Localization and Translational Control

large set of maternal mRNAs in the early embryo, including nos, and targeting them for decay (Semotok et al. 2005; Zaessinger et al. 2006; Tadros et al. 2007). Thus, nos mRNA is repressed in two distinct ways by Smg: by capdependent translational repression and by deadenylation of the silenced transcript (Fig. 3). Osk relieves Smg/CCR4-dependent deadenylation of nos, thus enabling its translation in the pole plasm (Zaessinger et al. 2006). Consistent with this, both the $5^{\prime}$ cap structure and the presence of a poly(A) tail are required for TCEmediated repression of a reporter construct in cell-free extracts prepared from ovaries, although the poly(A) tail does not affect repression in similar extracts prepared from early embryos (Andrews et al. 2011). Mutational analysis sug- gests that Glo is required for both the cap-dependent and poly(A)-dependent types of repression, although the mechanisms for its function remain unclear.

Translational regulation of ten other mRNAs that localize to the pole plasm at a similar developmental stage as nos was compared with the regulation of nos itself (Rangan et al. 2009). In all cases, the $3^{\prime}$ UTRs were sufficient to drive posterior localization and temporally restricted patterns of translation of the mRNAs. Often translational activation correlated with an increase in poly(A) tail length, but surprisingly for at least two of the mRNAs ( $p g c$ and $g c l$ ), reduction of orb activity had little effect on translation. Consistent with other results, this may indicate that it is more critical to regulate
A
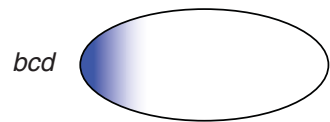

Bcd

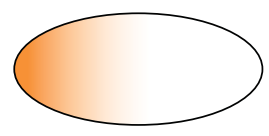

C

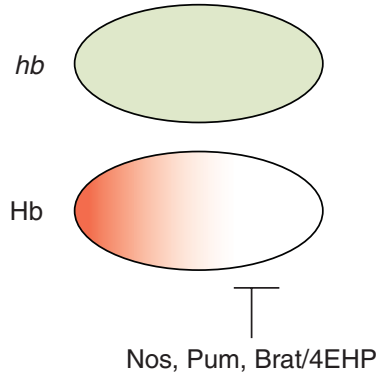

B
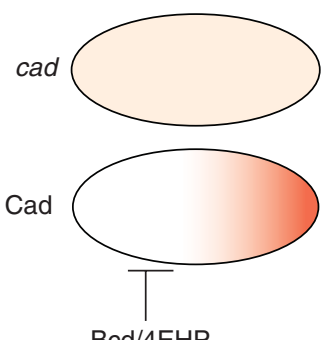

$\mathrm{Bcd} / 4 \mathrm{EHP}$

D
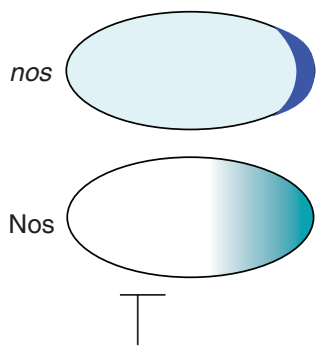

Figure 3. Mechanisms of establishing protein gradients in the early embryo prior to the onset of zygotic transcription. (A) Maternally expressed $b c d$ mRNA (top panel) is localized in a steep gradient at the anterior pole. Bcd protein (lower panel) is translated from that localized mRNA and diffuses toward the posterior. $(B)$ Maternally-expressed cad mRNA (top panel) is uniformly distributed. Translation of cad mRNA is, however, repressed by Bcd-mediated recruitment of $4 \mathrm{EHP}$, resulting in a posterior-to-anterior gradient of Cad protein (lower panel) that is a mirror image of the Bcd gradient. (C) Maternally expressed $h b$ mRNA (top panel) is uniformly distributed. Translation of $h b$ mRNA is repressed by a complex of Nos, Pum, and Brat, that recruits $4 \mathrm{EHP}$ and probably other negative regulators to restrict $\mathrm{Hb}$ protein (lower panel) to the anterior half of the embryo. (D) Maternally expressed nos mRNA (top panel) is enriched at the posterior pole but present elsewhere. Translation of nos outside the posterior is repressed by Smg, which can recruit the repressor protein Cup and also the CCR4 deadenylase complex. Unlocalized nos is also targeted by piRNAs (not shown). Nos protein (lower panel) is translated from posteriorly-localized nos that is protected from degradation and repression. 
P. Lasko

deadenylation rather than polyadenylation in regulating translation.

\section{EHP, AN ALTERNATE CAP-BINDING PROTEIN, REPRESSES TRANSLATION OF CAUDAL AND HUNCHBACK mRNAs}

Caudal (Cad), a transcription factor, is a master regulator of posterior patterning in many insects (Olesnicky et al. 2006). In Drosophila maternally expressed Cad forms a posteriorto-anterior gradient in the early embryo, and although its function is somewhat redundant with other regulatory factors it is nevertheless involved in activating posterior-specific zygotic genes (Schulz and Tautz 1995). In a role different from its function as a transcription factor, Bcd represses translation of cad mRNA, thus producing a gradient of Cad protein that is the mirror image of the Bcd gradient (Fig. 3) (Dubnau and Struhl 1996, Rivera-Pomar et al. 1996). Bcd binds to the $3^{\prime}$ UTR and recruits 4E homology protein (4EHP), an eIF4E-related cap binding protein that cannot bind eIF4G (Hernández et al. 2005), and thus cannot nucleate assembly of an active cap-binding complex (Cho et al. 2005). Females homozygous for a $4 E H P$ allele produce embryos with anterior defects, like those produced by $b c d$ mutants, that fail to repress cad translation in the anterior. These phenotypes could be rescued by $4 E H P$ transgenic constructs, but not by constructs producing mutant forms of 4EHP that were abrogated for binding to the structure or to Bcd. Similarly, transgenically produced forms of Bcd that were abrogated for $4 \mathrm{EHP}$ binding could not repress cad translation. These results showed that a complex of 4EHP and Bcd, interacting with the cap structure and the $3^{\prime}$ UTR, respectively, circularizes cad mRNA and renders it translationally inactive.

4EHP was later shown to be involved in repression of $h b$ mRNA in the posterior of the embryo (Fig. 3) (Cho et al. 2006), which had long been known to involve formation of a complex including Nos, Pum, Brain Tumor (Brat, an NHL-domain containing protein), and an element in the $h b 3^{\prime}$ UTR called the Nanos-response element (NRE) (Sonoda and Wharton
2001). In the case of $h b, 4 \mathrm{EHP}$ is recruited to the $5^{\prime}$ cap structure through an interaction with the NHL domain of Brat. As the binding sites for $4 \mathrm{EHP}$ on Bcd and Brat are not similar in sequence, and the latter does not resemble an eIF4E binding motif, it is possible that the interaction between 4EHP and Brat is indirect.

The translational repressor Pum is involved in many cellular and developmental processes in Drosophila other than embryonic patterning, including restriction of Cyclin B expression to the germline (Kadyrova et al. 2007), regulation of sodium current in motoneurons (Muraro et al. 2008), regulation of presynaptic morphology (Menon et al. 2004), regulation of dendrite morphogenesis in peripheral neurons (Ye et al. 2004), and maintenance of germline stem cell self-renewal (Gilboa and Lehmann 2004; Wang and Lin 2004; Szakmary et al. 2005; Li et al. 2009; Kim et al. 2010). Pum binds to a consensus sequence UGUANAUA (Gerber et al. 2006) and frequently operates in a complex with Nos. Often, Pum repression is independent of the cap structure and 4EHP, involving instead CCR4mediated deadenylation of its target mRNAs (Wreden et al. 1997; Gamberi et al. 2002; Goldstrohm et al. 2006). A recent study provides evidence that Nos is not always required for Pum activity, and that regions outside the Pum Cterminal domain that binds Nos and Brat possess substantial translational repressor activity (Weidmann and Goldstrohm 2012).

\section{VASA (VAS) IS A TRANSLATIONAL ACTIVATOR OF SPECIFIC GERM-LINE mRNAs}

Activators of translation of specific mRNAs have not been identified as frequently as repressors, and less is known about their function. One translational activator that is involved in Drosophila embryonic development is Vas, a DEADbox type RNA helicase. Complete loss of Vas blocks oogenesis and results in female sterility, whereas females homozygous for weaker vas alleles produce embryos that lack a germ line and posterior somatic segments. Vas binds to eIF5B, a translation factor that functions in ribosomal subunit joining, and mutations in vas and eIF5B 
genetically interact (Carrera et al. 2000). Severe vas mutations strongly reduce Grk accumulation in the oocyte (Styhler et al. 1998; Tomancak et al. 1998). A mutant form of Vas (Vas $\Delta 617)$ was generated whose ability to bind eIF5B was reduced 10-fold in yeast two-hybrid assays (Johnstone and Lasko 2004). Oocytes that express only Vas $\Delta 617$ fail to accumulate normal levels of Grk, suggesting that Vas activates grk translation through an interaction with eIF5B. Vas has also been shown to bind specifically to a U-rich motif present in the $3^{\prime}$ UTR of another mRNA, mei$P 26$, and to positively regulate its translation in germ cells through that interaction (Liu et al. 2009). Again, the Vas $\Delta 617$ mutation abrogates the effect.

Like many of the RNA binding proteins discussed in this review, Vas appears to have more than one function. It is a component of nuage, organelles that are involved in piRNA-mediated transposon silencing, and it has recently been implicated in regulating mitotic chromosome condensation in the Drosophila germline (Pek and Kai 2011). Dependent on the activities of $a u b$ and $s p n-E$, two piRNA pathway genes, Vas accumulates in perichromosomal foci during mitosis, and facilitates the recruitment of Barren, which in turn is required for correct chromosome condensation and segregation. This function of Vas appears to be independent of translation, as the Vas $\Delta 617$ mutant form operates normally in this regard.

\section{FUTURE DIRECTIONS}

In this field, some simple models have given way to more complicated ones over the past several years, and this trend will likely continue, because more extensive analysis has in many cases revealed novel unexpected activities for proteins and regulatory elements that were thought to be fully understood. Cup, the BREs, and perhaps Pum are just some examples of this. On first glance it seems perhaps illogical that many molecules involved in mRNA localization and translational control cannot be assigned a unitary function. What must be remembered, however, is that mRNAs and the proteins that regulate them are contained within a heterogeneous and highly dynamic set of RNPs, and that a given mRNA or protein might be a component of many different species of RNP at different developmental times or in different cellular or spatial positions. If we consider that the RNPs, not individual molecules, are the real functional units in translational regulation, manipulation of a single gene that encodes a single RNP component might actually disrupt many different species of RNP, and thus lead to multiple effects. Advances in quantitative imaging and proteomics (see, for instance, Slobodin and Gerst 2011) will likely make it possible to more fully characterize the panoply of RNPs that are involved in mRNA localization and translational control in Drosophila oocytes in upcoming years, which will be a critical step forward in developing a deeper understanding of these processes.

\section{REFERENCES}

Andrews S, Snowflack DR, Clark IE, Gavis ER. 2011. Multiple mechanisms collaborate to repress nanos translation in the Drosophila ovary and embryo. RNA 17: 967-977.

Arnott S, Hukins DW, Dover SD. 1972. Optimised parameters for RNA double-helices. Biochem Biophys Res Commun 48: 1392-1399.

Babu K, Cai Y, Bahri S, Yang X, Chia W. 2004. Roles of Bifocal, Homer, and F-actin in anchoring Oskar to the posterior cortex of Drosophila oocytes. Genes Dev 18: $138-143$.

Bashirullah A, Halsell SR, Cooperstock RL, Kloc M, Karaiskakis A, Fisher WW, Fu W, Hamilton JK, Etkin LD, Lipshitz HD. 1999. Joint action of two RNA degradation pathways controls the timing of maternal transcript elimination at the midblastula transition in Drosophila melanogaster. EMBO J 18: 2610-2620.

Bastock R, St Johnston D. 2008. Drosophila oogenesis. Curr Biol 18: R1082-R1087.

Becalska AN, Gavis ER. 2009. Lighting up mRNA localization in Drosophila oogenesis. Development 136: 2493 2503.

Becalska AN, Kim YR, Belletier NG, Lerit DA, Sinsimer KS, Gavis ER. 2011. Aubergine is a component of a nanos RNA localization complex. Dev Biol 349: 46-52.

Benoit B, He CH, Zhang F, Votruba SM, Tadros W, Westwood JT, Smibert CA, Lipshitz HD, Theurkauf WE. 2009a. An essential role for the RNA-binding protein Smaug during the Drosophila maternal-to-zygotic transition. Development 136: 923-932.

Benoit P, Papin C, Kwak JE, Wickens M, Simonelig M. 2009b. PAP- and GLD-2 type poly(A) polymerases are required sequentially in cytoplasmic polyadenylation and oogenesis in Drosophila. Development 135: 19691979. 
P. Lasko

Bergsten SE, Gavis ER. 1999. Role for mRNA localization in translational activation but not spatial restriction of nanos mRNA. Development 126: 659-669.

Berleth T, Burri M, Thoma G, Bopp D, Richstein S, Frigerio G, Noll M, Nüsslein-Volhard C. 1988. The role of localization of bicoid RNA in organizing the anterior pattern of the Drosophila embryo. EMBO J 7: 1749-1756.

Besse F, Lopez de Quinto S, Marchand V, Trucco A, Ephrussi A. 2009. Drosophila PTB promotes formation of highorder RNP particles and represses oskar translation. Genes Dev 23: 195-207.

Braat AK, Yan N, Arn E, Harrison D, Macdonald PM. 2004. Localization-dependent Oskar protein accumulation; control after the initiation of translation. Dev Cell 7: $125-131$.

Bullock SL, Ringel I, Ish-Horowicz D, Lukavsky PJ. 2010. $\mathrm{A}^{\prime}$-form RNA helices are required for cytoplasmic mRNA transport in Drosophila. Nat Struct Mol Biol 17: 703-709.

Bushati N, Stark A, Brennecke J, Cohen SM. 2008. Temporal specificity of miRNAs and their targets during the maternal-to-zygotic transition in Drosophila. Curr Biol 18: 501-506.

Caceres L, Nilson LA. 2005. Production of gurken in the nurse cells is sufficient for axis determination in the Drosophila oocyte. Development 132: 2345-2353.

Carrera P, Johnstone O, Nakamura A, Casanova J, Jäckle H, Lasko P. 2000. VASA mediates translation through interaction with a Drosophila yIF2 homolog. Mol Cell 5: 181-187.

Castagnetti S, Ephrussi A. 2003. Orb and a long poly(A) tail are required for efficient oskar translation at the posterior pole of the Drosophila oocyte. Development 130: $835-$ 843.

Cha BJ, Koppetsch BS, Theurkauf WE. 2001. In vivo analysis of Drosophila bicoid mRNA localization reveals a novel microtubule-dependent axis specification pathway. Cell 106: 35-46.

Chang C-W, Nashchekin D, Wheatley L, Irion U, Dahlgaard K, Montague TG, Hall J, St Johnston D. 2011. Anteriorposterior axis specification in Drosophila oocytes: Identification of novel bicoid and oskar localization factors. Genetics 188: 883-896.

Chekulaeva M, Hentze MW, Ephrussi A. 2006. Bruno acts as a dual repressor of oskar translation, promoting mRNA oligomerization and formation of silencing particles. Cell 124: 521-533.

Chen Y, Pane A, Schüpbach T. 2007. cutoff and aubergine mutations result in retrotransposon upregulation and checkpoint activation in Drosophila. Curr Biol 17: 637642.

Chicoine J, Benoit P, Gamberi C, Paliouras M, Simonelig M, Lasko P. 2007. Bicaudal-C recruits CCR4-NOT deadenylase to target mRNAs and regulates oogenesis, cytoskeletal organization, and its own expression. Dev Cell 13: 691-704.

Cho PF, Poulin F, Cho-Park YA, Cho-Park IB, Chicoine JD, Lasko P, Sonenberg N. 2005. A new paradigm for translational control: Inhibition via $5^{\prime}-3^{\prime}$ mRNA tethering by Bicoid and the eIF4E cognate 4EHP. Cell 121: 411-423.

Cho PF, Gamberi C, Cho-Park YA, Cho-Park IB, Lasko P, Sonenberg N. 2006. Cap-dependent translational inhibi- tion establishes two opposing morphogen gradients in Drosophila embryos. Curr Biol 16: 2035-2041.

Clark A, Meignin C, Davis I. 2007. A Dynein-dependent shortcut rapidly delivers axis determination transcripts into the Drosophila oocyte. Development 134: 19551965.

Coll O, Villalba A, Bussotti G, Notredame C, Gebauer F. 2010. A novel, noncanonical mechanism of cytoplasmic polyadenylation operates in Drosophila embryogenesis. Genes Dev 24: 129-134.

Cook HA, Koppetsch BS, Wu J, Theurkauf WE. 2004. The Drosophila SDE3 homolog armitage is required for oskar mRNA silencing and embryonic axis specification. Cell 116: $817-829$.

Crucs S, Chatterjee S, Gavis ER. 2000. Overlapping but distinct RNA elements control repression and activation of nanos translation. Mol Cell 5: 457-467.

Cui J, Sackton KL, Homer VL, Kumar KE, Wolfner MF. 2008. Wispy, the Drosophila homolog of GLD-2, is required during oogenesis and egg activation. Genetics 178: 2017-2029.

Delanoue R, Herpers B, Soetaert J, Davis I, Rabouille C. 2007. Drosophila Squid/hnRNP helps Dynein switch from a gurken mRNA transport motor to an ultrastructural static anchor in sponge bodies. Dev Cell 13: $523-$ 538.

Dienstbier M, Boehl F, Li X, Bullock SL. 2009. Egalitarian is a selective RNA-binding protein linking mRNA localization signals to the dynein motor. Genes Dev 23: $1546-$ 1558.

Driever W, Nüsslein-Volhard C. 1988. The Bicoid protein determines position in the Drosophila embryo in a concentration-dependent manner. Cell 54: 95-104.

Dubnau J, Struhl G. 1996. RNA recognition and translational regulation by a homeodomain protein. Nature 379: 694-699.

Ferrandon D, Elphick L, Nüsslein-Volhard C, St. Johnston D. 1994. Staufen protein associates with the $3^{\prime}$ UTR of bicoid mRNA to form particles that move in a microtubule-dependent manner. Cell 79: 1221-1232.

Findley SD, Tamanaha M, Clegg NJ, Ruohola-Baker H. 2003. maelstrom, a Drosophila spindle-class gene, encodes a protein that colocalizes with Vasa and RDE1/AGO1 homolog, Aubergine, in nuage. Development 130: 859871.

Forrest KM, Gavis ER. 2003. Live imaging of endogenous mRNA reveals a diffusion and entrapment mechanism for nanos mRNA localization in Drosophila. Curr Biol 13: $1159-1168$.

Forrest KM, Clark IE, Jain RA, Gavis ER. 2004. Temporal complexity within a translational control element in the nanos mRNA. Development 131: 5849-5857.

Gamberi C, Peterson DS, He L, Gottlieb E. 2002. An anterior function for the Drosophila posterior determinant Pumilio. Development 129: 2699-2710.

Gavis ER, Chatterjee S, Ford NR, Wolff LJ. 2008. Dispensability of nanos mRNA localization for abdominal patterning but not for germ cell development. Mech Dev 125: 81-90.

Gerber AP, Luschnig S, Krasnow MA, Brown PO, Herschlag D. 2006. Genome-wide identification of mRNAs 
associated with the translational regulator PUMILIO in Drosophila melanogaster. Proc Natl Acad Sci 103: 4487-4492.

Gilboa L, Lehmann R. 2004. Repression of primordial germ cell differentiation parallels germ line stem cell maintenance. Curr Biol 18: 981-986.

Goldstrohm AC, Hook BA, Seay DJ, Wickens M. 2006. PUF proteins bind Pop2p to regulate messenger RNAs. Nat Struct Mol Biol 13: 533-539.

González-Reyes A, Elliott H, St Johnston D. 1995. Polarization of both major body axes in Drosophila by gurkentorpedo signaling. Nature 375: 654-658.

Gregor T, Wieschaus EF, McGregor AP, Bialek W, Tank DW. 2007a. Stability and nuclear dynamics of the Bicoid morphogen gradient. Cell 130: 141-152.

Gregor T, Tank DW, Wieschaus EF, Bialek W. 2007b. Probing the limits to positional information. Cell 130: 153-164.

Hachet O, Ephrussi A. 2004. Splicing of oskar RNA in the nucleus is coupled to its cytoplasmic localization. Nature 428: 959-963.

Hernández G, Altmann M, Sierra JM, Urlaub H, Diez del Corral R, Schwartz P, Rivera-Pomar R. 2005. Functional analysis of seven genes encoding eight translation initiation factor 4E (eIF4E) isoforms in Drosophila. Mech Dev 122: $529-543$.

Hoogenraad CC, Wulf P, Schiefermeier N, Stepanova T, Galjart N, Small JV, Grosveld F, de Zeeuw CI, Akhmanova A. 2003. Bicaudal D induces selective dynein-mediated microtubule minus end-directed transport. $E M B O J$ 22: 6004-6015.

Houchmandzadeh B, Wieschaus E, Leibler S. 2002. Establishment of developmental precision and proportions in the early Drosophila embryo. Nature 415: 798-802.

Huynh JR, Munro TP, Smith-Litière K, Lepesant JA, St. Johnston D. 2004. The Drosophila hnRNP A/B homo$\log$, Hrp48, is specifically required for a distinct step in osk mRNA localization. Dev Cell 6: 625-635.

Igreja C, Izaurralde E. 2011. CUP promotes deadenylation and inhibits decapping of mRNA targets. Genes Dev 25: 1955-1967.

Irion U, St. Johnston D. 2007. bicoid RNA localization requires specific binding of an endosomal sorting complex Nature 445: 554-558.

Jain R, Gavis ER. 2008. The Drosophila hnRNP M homolog, Rumpelstiltskin, regulates nanos mRNA localization. Development 135: 973-982.

Jambor H, Brunel C, Ephrussi A. 2011. Dimerization of oskar $3^{\prime}$ UTRs promotes hitchhiking for RNA localization in the Drosophila oocyte. RNA 17: 2049-2057.

Januschke J, Gervais L, Gillet L, Keryer G, Bornens M, Guichet A. 2006. The centrosome-nucleus complex and microtubule organization in the Drosophila oocyte. Development 133: 129-139.

Jaramillo AM, Weil TT, Goodhouse J, Gavis ER, Schüpbach T. 2008. The dynamics of fluorescently labelled endogenous gurken mRNA in Drosophila. J Cell Sci 121: 887894.

Jeske M, Moritz B, Anders A, Wahle E. 2011. Smaug assembles an ATP-dependent stable complex repressing nanos mRNA translation at multiple levels. EMBO J 30: $90-$ 103.
Johnstone O, Lasko P. 2004. Interaction with eIF5B is essential for Vasa function during development. Development 131: 4167-4178.

Kadyrova LY, Habara Y, Lee TH, Wharton RP. 2007. Translational control of maternal Cyclin B mRNA by Nanos in the Drosophila germline. Development 134: 1519-1527.

Kalifa Y, Huang T, Rosen LN, Chatterjee S, Gavis ER. 2006. Glorund, a Drosophila hnRNP F/H homolog, is an ovarian repressor of nanos translation. Dev Cell 10: 291-301.

Kalifa Y, Armenti ST, Gavis ER. 2009. Glorund interactions in the regulation of gurken and oskar mRNAs. Dev Biol 326: $68-74$.

Kim JY, Lee YC, Kim C. 2010. Direct inhibition of Pumilio activity by Bam and Bgcn in Drosophila germ line stem cell differentiation. J Biol Chem 285: 4741-4746.

Kim-Ha J, Kerr K, Macdonald PM. 1995. Translational regulation of oskar mRNA by Bruno, an ovarian RNA-binding protein, is essential. Cell 81: 403-412.

King RC. 1970. Ovarian development in Drosophila melanogaster. Academic Press, New York.

Klattenhoff C, Bratu DP, McGinnis-Schultz N, Koppetsch BS, Cook HA, Theurkauf WE. 2007. Drosophila rasiRNA pathway mutations disrupt embryonic axis specification through activation of an ATR/Chk2 DNA damage response. Dev Cell 12: 45-55.

Krauss J, López de Quinto S, Nüsslein-Volhard C, Ephrussi A. 2009. Myosin-V regulates oskar mRNA localization in the Drosophila oocyte. Curr Biol 19: 1058-1063.

Kugler JM, Lasko P. 2009. Localization, anchoring, and translational control of oskar, gurken, bicoid, and nanos mRNA during Drosophila oogenesis. Fly 3: 15-28.

Lan L, Lin S, Zhang S, Cohen RS. 2010. Evidence for a transport-trap mode of Drosophila melanogaster gurken mRNA localization. PLoS ONE 5: e15448.

Lécuyer E, Yoshida H, Parthasarathy N, Alm C, Babak T, Cerovina T, Hughes TR, Tomancak P, Krause HM. 2007. Global analysis of mRNA localization reveals a prominent role in organizing cellular architecture and function. Cell 131: 174-187.

Li Y, Minor NT, Park JK, McKearin DM, Maines JZ. 2009. Bam and Bgcn antagonize Nanos-dependent germ-line stem cell maintenance. Proc Natl Acad Sci 106: 93049309.

Lim AK, Kai T. 2007. Unique germ-line organelle, nuage, functions to repress selfish genetic elements in Drosophila melanogaster. Proc Natl Acad Sci 104: 6714-6719.

Little SC, Tkacik G, Kneeland TB, Wieschaus EF, Gregor T. 2011. The formation of the Bicoid gradient requires protein movement from anteriorly localized mRNA. PLoS Biol 9: e1000596.

Liu J, Ma J. 2011. Fates-shifted is an F-box protein that targets Bicoid for degradation and regulates developmental fate determination in Drosophila embryos. Nat Cell Biol 13: 22-29.

Liu N, Han H, Lasko P. 2009. Vasa promotes Drosophila germline stem cell differentiation by activating mei-P26 translation by directly interacting with a (U)-rich motif in its 3' UTR. Genes Dev 23: 2742-2752.

Löhr U, Chung HR, Beller M, Jäckle H. 2009. Antagonistic action of Bicoid and the repressor Capicua determines 
P. Lasko

the spatial limits of Drosophila head gene expression domains. Proc Natl Acad Sci 106: 21695-21700.

Lucchetta EM, Vincent ME, Ismagilov RF. 2008. A precise Bicoid gradient is nonessential during cycles $11-13$ for precise patterning in the Drosophila blastoderm. PLoS ONE 3: e3651.

MacDougall N, Clark A, MacDougall E, Davis I. 2003. Drosophila gurken (TGF $\alpha$ ) mRNA localizes as particles that move within the oocyte in two dynein-dependent steps. Dev Cell 4: 307-319.

Markussen F-H, Michon AM, Breitwieser W, Ephrussi A. 1995. Translational control of oskar generates short OSK, the isoform that induces pole plasma assembly. Development 121: 3723-3732.

Menon KP, Sanyal S, Habara Y, Sanchez R, Wharton RP, Ramaswami M, Zinn K. 2004. The translational repressor Pumilio regulates presynaptic morphology and controls postsynaptic accumulation of translation factor eIF-4E. Neuron 44: 663-676.

Mhlanga MM, Bratu DP, Genovesio A, Rybarska A, Chenouard N, Nehrbass U, Olivo-Marin J-C. 2009. In vivo colocalisation of oskar mRNA and trans-acting proteins revealed by quantitative imaging of the Drosophila oocyte. PLoS ONE 4: e6241.

Micklem DR, Adams J, Grünert S, St Johnston D. 2000. Distinct roles of two conserved Staufen domains in oskar mRNA localization and translation. EMBO J 19: $1366-$ 1377.

Mische S, Li M, Serr M, Hays TS. 2007. Direct observation of regulated ribonucleoprotein transport across the nurse cell/oocyte boundary. Mol Biol Cell 18: 2254-2263.

Moon W, Hazelrigg T. 2004. The Drosophila microtubuleassociated protein Mini spindles is required for cytoplasmic microtubules in oogenesis. Curr Biol 14: 1957-1961.

Muraro NI, Weston AJ, Gerber AP, Luschnig S, Moffat KG Baines RA. 2008. Pumilio binds para mRNA and requires Nanos and Brat to regulate sodium current in Drosophila motoneurons. J Neurosci 28: 2099-2109.

Nakamura A, Sato K, Hanyu-Nakamura K. 2004. Drosophila Cup is an eIF4E binding protein that associates with Bruno and regulates oskar mRNA translation in oogenesis. Dev Cell 6: 69-78.

Navarro C, Puthalakath H, Adams JM, Strasser A, Lehmann R. 2004. Egalitarian binds dynein light chain to establish oocyte polarity and maintain oocyte fate. Nat Cell Biol 6: 427-435.

Nelson MR, Leidal AM, Smibert CA. 2004. Drosophila Cup is an eIF4E-binding protein that functions in Smaugmediated translational repression. EMBO J 23: 150-159.

Norvell A, Debec A, Finch D, Gibson L, Thoma B. 2005. Squid is required for efficient posterior localization of oskar mRNA during Drosophila oogenesis. Dev Genes Evol 215: 340-349.

Ochoa-Espinosa A, Yu D, Tsirigos A, Struffi P, Small S. 2009. Anterior-posterior positional information in the absence of a strong Bicoid gradient. Proc Natl Acad Sci 106: 3823 3828.

Olesnicky EC, Brent AE, Tonnes L, Walker M, Pultz MA, Leaf D, Desplan C. 2006. A caudal mRNA gradient controls posterior development in the wasp Nasonia. Development 133: 3973-3982.
Palacios IM, Gatfield D, St. Johnston D, Izaurralde E. 2004 An eIF4AIII-containing complex required for mRNA localization and nonsense-mediated mRNA decay. Nature 427: 753-757.

Pane A, Wehr K, Schüpbach T. 2007. zucchini and squash encode two putative nucleases required for rasiRNA production in the Drosophila germline. Dev Cell 12: 851862.

Pek JW, Kai T. 2011. A role for Vasa in regulating mitotic chromosome condensation in Drosophila. Curr Biol 21: 39-44.

Rangan P, DeGennaro M, Jaime-Bustamante K, Coux RX, Martinho RG, Lehmann R. 2009. Temporal and spatial control of germ-plasm RNAs. Curr Biol 19: 72-77.

Reveal B, Yan N, Snee MJ, Pai CI, Gim Y, Macdonald PM. 2010. BREs mediate both repression and activation of oskar mRNA translation and act in trans. Dev Cell 18: 496-502.

Riechmann V, Ephrussi A. 2004. Par-1 regulates bicoid mRNA localisation by phosphorylating Exuperantia. Development 131: 5897-5907.

Rivera-Pomar R, Niessing D, Schmidt-Ott U, Gehring WJ, Jäckle H. 1996. RNA binding and translational suppression by Bicoid. Nature 379: 746-749.

Roth S, Neuman-Silberberg FS, Barcelo G, Schüpbach T. 1995. cornichon and the EGF receptor signalling process are necessary for both anterior-posterior and dorsal-ventral pattern formation in Drosophila. Cell 81: 967-978.

Rouget C, Papin C, Boureux A, Meunier A-C, Franco B, Robine N, Lai EC, Pelisson A, Simonelig M. 2010. Maternal mRNA deadenylation and decay by the piRNA pathway in the early Drosophila embryo. Nature 467: $1128-1132$.

Saffman EE, Styhler S, Rother K, Li W, Richard S, Lasko P. 1998. Premature translation of oskar in oocytes lacking the RNA-binding protein Bicaudal-C. Mol Cell Biol 18: 4855-4862.

Schnorrer F, Bohmann K, Nüsslein-Volhard C. 2000. The molecular motor Dynein is involved in targeting Swallow and bicoid RNA to the anterior pole of Drosophila oocytes. Nat Cell Biol 2: 185-190.

Schnorrer F, Luschnig S, Koch I, Nüsslein-Volhard C. 2002. Gamma-tubulin37C and gamma-tubulin ring complex protein 75 are essential for bicoid RNA localization during Drosophila oogenesis. Dev Cell 3: 685-696.

Schulz C, Tautz D. 1995. Zygotic Caudal regulation by Hunchback and its role in abdominal segment formation of the Drosophila embryo. Development 121: 1023-1028.

Semotok JL, Cooperstock RL, Pinder BD, Vari HK, Lipshitz HD, Smibert CA. 2005. Smaug recruits the CCR4/POP2/ NOT deadenylase complex to trigger maternal transcript localization in the early Drosophila embryo. Curr Biol 15: 284-294.

Sinsimer KS, Jain RA, Chatterjee S, Gavis ER. 2011. A late phase of germ plasm accumulation during Drosophila oogenesis requires Lost and Rumpelstiltskin. Development 138: 3431-3440.

Slobodin B, Gerst JE. 2011. RaPID: An aptamer-based mRNA affinity purification technique for the identification of RNA and protein factors in ribonucleoprotein complexes. Methods Mol Biol 714: 387-406. 
mRNA Localization and Translational Control

Snee M, Benz D, Jen J, Macdonald PM. 2008. Two distinct domains of Bruno bind specifically to the oskar mRNA. RNA Biol 5: 1-9.

Sonoda J, Wharton RP. 2001. Drosophila brain tumor is a translational repressor. Genes Dev 15: 762-773.

Spirov A, Fahmy K, Schneider M, Frei E, Nöll M, Baumgartner S. 2009. Formation of the bicoid morphogen gradient: An mRNA gradient dictates the protein gradient. Development 136: 605-614.

St Johnston D, Driever W, Berleth T, Richstein S, NüssleinVolhard C. 1989. Multiple steps in the localization of bicoid RNA to the anterior pole of the Drosophila oocyte. Development 107 (Suppl): 13-19.

Styhler S, Nakamura A, Swan A, Suter B, Lasko P. 1998. vasa is required for GURKEN accumulation in the oocyte, and is involved in oocyte differentiation and germline cyst development. Development 125: 1569-1578.

Szakmary A, Cox DN, Wang Z, Lin H. 2005. Regulatory relationship among piwi, pumilio, and bag-of-marbles in Drosophila germline stem cell self-renewal and differentiation. Curr Biol 15: 171-178.

Tadros W, Goldman AL, Babak T, Menzies T, Vardy L, OrrWeaver T, Hughes TR, Westwood JT, Smibert CA, Lipshitz HD. 2007. SMAUG is a major regulator of maternal mRNA destabilization in Drosophila and its translation is activated by the PAN GU kinase. Dev Cell 12: 143-155.

Tanaka T, Nakamura A. 2008. The endocytic pathway acts downstream of Oskar in Drosophila germ plasm assembly. Development 135: 1107-1117.

Tanaka T, Kato Y, Matsuda K, Hanyu-Nakamura K, Nakamura A. 2011. Drosophila Mon2 couples Oskar-induced endocytosis with actin remodeling for cortical anchorage of the germ plasm. Development 138: 2523-2532.

Theurkauf WE, Hazelrigg TI. 1998. In vivo analyses of cytoplasmic transport and cytoskeletal organization during Drosophila oogenesis: Characterization of a multi-step anterior localization pathway. Development 125: 36553666.

Tomancak P, Guichet A, Zavorszky P, Ephrussi A. 1998. Oocyte polarity depends on regulation of gurken by Vasa. Development 125: 1723-1732.

Tomancak P, Berman BP, Beaton A, Weiszmann R, Kwan E, Hartenstein V, Celniker SE, Rubin GM. 2007. Global analysis of patterns of gene expression during Drosophila embryogenesis. Genome Biol 8: R145.

Tomari Y, Du T, Haley B, Schwarz DS, Bennett R, Cook HA, Koppetsch BS, Theurkauf WE, Zamore PD. 2004. RISC assembly defects in the Drosophila RNAi mutant armitage. Cell 119: 831-841.

Van De Bor V, Hartswood E, Jones C, Finnegan D, Davis I. 2005. gurken and the I factor retrotransposon RNAs share common localization signals and machinery. Dev Cell 9: $51-62$.
Vanzo N, Oprins A, Xanthakis D, Ephrussi A, Rabouille C. 2007. Stimulation of endocytosis and actin dynamics by Oskar polarizes the Drosophila oocyte. Dev Cell 12: $543-$ 555.

Vogt N, Koch I, Schwarz H, Schnörrer F, Nüsslein-Volhard C. 2006. The gammaTuRC components Grip75 and Grip128 have an essential microtubule-anchoring function in the Drosophila germline. Development 133: $3963-$ 3972.

Walser CB, Lipshitz HD. 2011. Transcript clearance during the maternal-to-zygotic transition. Curr Opin Genet Dev 21: $431-443$.

Wang Z, Lin H. 2004. Nanos maintains germline stem cell self-renewal by preventing differentiation. Science 303: 2016-2019.

Weidmann CA, Goldstrohm AC. 2012. Drosophila Pumilio protein contains multiple autonomous repression domains that regulate mRNAs independently of Nanos and Brain Tumor. Mol Cell Biol 32: 527-540.

Weil TT, Forrest KM, Gavis ER. 2006. Localization of bicoid mRNA in late oocytes is maintained by continual active transport. Dev Cell 11: 251-262.

Weil TT, Xanthakis D, Parton R, Dobbie I, Rabouille C, Gavis ER, Davis I. 2010. Distinguishing direct from indirect roles for bicoid mRNA localization factors. Development 137: 169-176.

Wilhelm JE, Mansfield J, Hom-Booher N, Wang S, Turck CW, Hazelrigg T, Vale RD. 2000. Isolation of a ribonucleoprotein complex involved in mRNA localization in Drosophila oocytes. J Cell Biol 148: 427-440.

Wreden C, Verrotti AC, Schisa JA, Lieberfarb ME, Strickland S. 1997. Nanos and Pumilio establish embryonic polarity in Drosophila by promoting posterior deadenylation of hunchback mRNA. Development 124: 3015-3023.

Yano T, López de Quinto S, Matsui Y, Shevchenko A, Shevchenko A, Ephrussi A. 2004. Hrp48, a Drosophila hnRNP A/B homolog, binds and regulates translation of oskar mRNA. Dev Cell 6: 637-648.

Ye B, Petritsch C, Clark IE, Gavis ER, Jan LY, Jan YN. 2004. Nanos and Pumilio are essential for dendrite morphogenesis in Drosophila peripheral neurons. Curr Biol 14: 314-321.

Zaessinger S, Busseau I, Simonelig M. 2006. Oskar allows nanos mRNA translation in Drosophila embryos by preventing its deadenylation by Smaug/CCR4. Development 133: $4573-4583$.

Zimyanin VL, Belaya K, Pecreaux J, Gilchrist MJ, Clark A, Davis I, St. Johnston D. 2008. In vivo imaging of oskar mRNA transport reveals the mechanism of posterior localization. Cell 134: 843-853. 


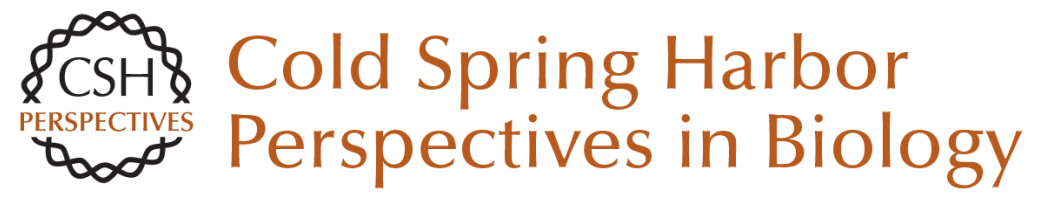

\section{mRNA Localization and Translational Control in Drosophila Oogenesis}

Paul Lasko

Cold Spring Harb Perspect Biol 2012; doi: 10.1101/cshperspect.a012294 originally published online August 3, 2012

\section{Subject Collection Protein Synthesis and Translational Control}

Tinkering with Translation: Protein Synthesis in Virus-Infected Cells

Derek Walsh, Michael B. Mathews and lan Mohr

Translational Control in Cancer Etiology

Davide Ruggero

A Molecular Link between miRISCs and Deadenylases Provides New Insight into the

Mechanism of Gene Silencing by MicroRNAs Joerg E. Braun, Eric Huntzinger and Elisa Izaurralde

Imaging Translation in Single Cells Using Fluorescent Microscopy Jeffrey A. Chao, Young J. Yoon and Robert $H$. Singer

mRNA Localization and Translational Control in Drosophila Oogenesis Paul Lasko

P-Bodies and Stress Granules: Possible Roles in the Control of Translation and mRNA Degradation Carolyn J. Decker and Roy Parker

Protein Secretion and the Endoplasmic Reticulum Adam M. Benham

From Cis-Regulatory Elements to Complex RNPs and Back

Fátima Gebauer, Thomas Preiss and Matthias W. Hentze
Toward a Genome-Wide Landscape of

Translational Control Ola Larsson, Bin Tian and Nahum Sonenberg

The Current Status of Vertebrate Cellular mRNA IRESs

Richard J. Jackson

Principles of Translational Control: An Overview John W.B. Hershey, Nahum Sonenberg and Michael B. Mathews

Regulation of mRNA Translation by Signaling Pathways

Philippe P. Roux and Ivan Topisirovic

The Mechanism of Eukaryotic Translation Initiation: New Insights and Challenges Alan G. Hinnebusch and Jon R. Lorsch

Single-Molecule Analysis of Translational Dynamics Alexey Petrov, Jin Chen, Seán O'Leary, et al.

Cytoplasmic RNA-Binding Proteins and the Control of Complex Brain Function Jennifer C. Darnell and Joel D. Richter

The Elongation, Termination, and Recycling

Phases of Translation in Eukaryotes Thomas E. Dever and Rachel Green

For additional articles in this collection, see http://cshperspectives.cshlp.org/cgi/collection/

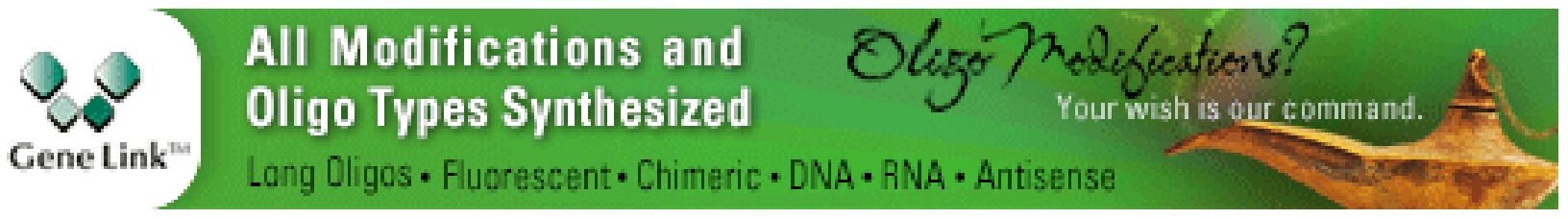


For additional articles in this collection, see http://cshperspectives.cshlp.org/cgi/collection/

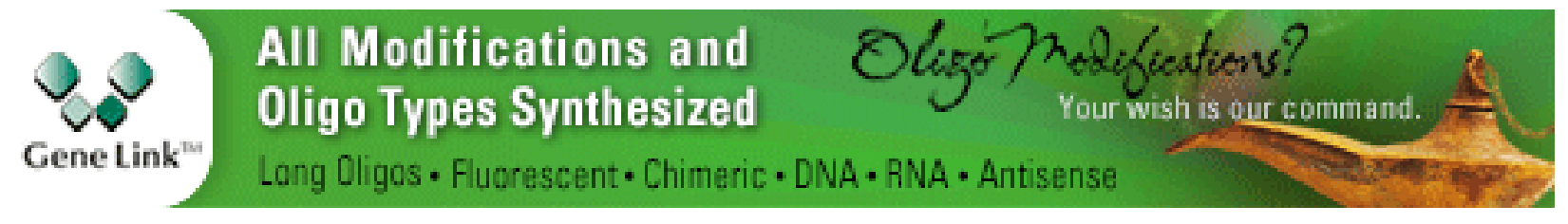

Copyright @ 2012 Cold Spring Harbor Laboratory Press; all rights reserved 